\title{
How integrating primary care and public health can improve population health outcomes: a view from Liverpool, UK
}

\section{Rachael Goslinga, Sandra M Davies ${ }^{b}$ and John A Hussey a,c,d}

a Liverpool Community Health NHS Trust, UK

b Liverpool City Council, UK

c The Elms Medical Centre, Liverpool, UK

d Corresponding author: john.hussey@LiverpoolCH.nhs.uk

\section{Article history}

Publication date: January 2016.

Citation: Gosling R, Davies SM, Hussey JA. How integrating primary care and public health can improve population health outcomes: a view from Liverpool, UK. Public Health Res Pract. 2016;26(1):e2611602. doi: http://dx.doi.org/10.17061/phrp2611602

\section{Key points}

- Determinants of health are wide-ranging and include how healthcare is organised

- Primary care is at the forefront of healthcare delivery and plays a significant role in improving population health

- Liverpool has a rich history of pioneering public health approaches. It is well placed to deliver improved population health through new commissioning arrangements; neighbourhood delivery, which builds on community assets; patient engagement; and greater use of primary care data

\begin{abstract}
Although primary care is at the forefront of delivering healthcare to the population, its role in preventing poor health has varied throughout history. Faced with growing demand on healthcare services and a rise in noncommunicable diseases, some health systems are attempting to integrate healthcare delivery with broader population health and wellbeing interventions.
\end{abstract}

Liverpool has a rich history of taking action to improve population health; this paper discusses a range of interventions that have taken place across the city. There is a renewed opportunity to systematise approaches to primary and secondary prevention, strengthened by the lead that general practitioners now have in commissioning health services and their accountability for improved population health outcomes through clinical commissioning groups. This is strongly articulated in the Healthy Liverpool program, a city-wide plan for health and care services.

This paper suggests that four key enablers strengthen delivery of public health priorities through primary care: maximising opportunities to identify risk factors for preventable disease, fully exploiting the data collected in primary care to plan and design services, responding to community needs and assets through community engagement, and addressing wider determinants of health through strong partnerships.

\section{Introduction}

Health is determined by multiple interconnecting factors, including genetics, lifestyle, socio-economic, cultural and environmental conditions. ${ }^{1}$ The quality, organisation and delivery of healthcare are important determinants of population and individual health, although estimates of their contribution vary from $15 \%$ to $43 \%$. $^{2}$ Primary care's role in preventing poor health was recognised by Liverpool general practitioner (GP) William Henry Duncan, known as 'Dr Duncan'3, in the mid-19th century, and was clearly articulated in the Ottawa Charter for Health Promotion 30 years ago. ${ }^{4}$ 
More recently, the National Health Service (NHS) 'Five year forward view's emphasised the need for a 'radical upgrade' in prevention. It proposes taking national action on major health risks, targeting prevention initiatives, increasing patient control and harnessing community assets. Primary care has always been an important partner contributing to this agenda. However, the focus on creating integrated models of care that meet local population needs, along with new arrangements placing primary care at the centre of commissioning health services and being accountable for population health outcomes, creates a renewed opportunity for primary care to focus on the prevention agenda at a community level.

In this paper, we reflect on our experiences of working in primary care and public health in Liverpool. We outline the historical context, provide some examples of effective local interventions and identify opportunities for systematising approaches to embed prevention within primary care.

\section{Liverpool - from Dr Duncan to the Healthy Liverpool program}

Liverpool (population 460000 ) is a city in north-west England with a rich history of public health. Health outcomes are worse than the average for England. Key indicators include 6 :

- $60 \%$ of people live in the most deprived neighbourhoods in the country

- One-third of children live in poverty

- Healthy life expectancy is 59 years. Life expectancy is 76 years for men and 80 years for women

- In the next 20 years, the number of people older than 60 is expected to increase by $30 \%$

- $10 \%$ of people have two or more long-term conditions

- In the more deprived communities, there is higher prevalence of comorbidities at a younger age.

The UK's first Medical Officer for Health - Dr Duncan - was appointed in Liverpool and was a GP. Dr Duncan recognised the association between his patients' health and their poor living conditions, and is credited with initiating a program that hugely improved population health. Liverpool pioneered the first health visiting service in the late 1800 s, a whole city program for tuberculosis screening in 1959 and the 'city health plan' in 1996. Public health as a specialist function was hosted within the local authority and then moved to the NHS in 1974 , which influenced its reach and focus in relation to primary care.

Since the World Health Organization's Alma-Ata declaration in $1978^{7}$, various attempts have been made to encourage general practice to carry out public health activities (Box 1), with varying success and some unintended consequences. ${ }^{8}$

During this time, the evidence supporting public health interventions being carried out by primary care practitioners has grown and is captured in several
Box 1. Public health activities involving general practitioners since the Alma-Ata declaration

1987: Liverpool becomes the founder city of the World Health Organization European Healthy Cities Initiative, with a specific aim to "re-orient local health and social care programmes to provide higher quality coordinated primary care" 9

1990: Introduction of the national general practitioner (GP) contract. This incentivised GPs to run 'health promotion clinics' and achieve certain targets for cervical screening and immunisation uptake

2001: Introduction of National Health Service public health targets to be delivered through primary care, such as improved cancer detection rates

2002: Establishment of Primary Care Trusts (PCTs). In Liverpool, the Director of Public Health was a joint appointment between Liverpool City Council and Liverpool PCT. This enabled closer collaboration between public health and primary health, as well as greater influence over the wider determinants of health and the commissioning of healthcare services

2004: Introduction of the Quality and Outcomes Framework for GPs. This incentivised GPs to engage in secondary prevention - for example, by keeping registers of patients with chronic disease

2012: Publication of the Health and Social Care Act. The public health specialist function was returned to Liverpool City Council. Clinical commissioning groups were established, with GPs responsible for commissioning health services and outcomes across the city

2015: Publication of the Healthy Liverpool program - a city-wide plan for population health, which provides a renewed opportunity for increased integration between primary care and population health ${ }^{10}$

National Institute for Health and Care Excellence (NICE) public health guidance documents. ${ }^{11}$

Integrating healthcare for the individual while addressing the health needs of the wider population is not new, and Liverpool is not unique in re-emphasising this. Other health systems - for example, the Alaskan natives' Nuka System of Care ${ }^{12}$, Cuba's National Health System ${ }^{13}$ and Jonkoping County Council in Sweden ${ }^{14}$ have developed population health approaches with some success.

\section{Delivering public health priorities through primary care teams}

Primary care teams interact with patients in their communities and are at the frontline of healthcare, with more than 340 million patient-to-GP consultations per year in England. We suggest that improved population 
health can be delivered through primary care in four key areas: identifying risk factors, improving use of primary care data, understanding community needs and using community assets, and taking action on the wider determinants of health.

\section{Identifying risk factors}

Identifying disease risk factors at an individual level and intervening early to mitigate illness is a key role for primary care. Many GPs already identify risk factors, such as the public health indicators included in the Quality and Outcomes Framework:

- Assessing risk for cardiovascular disease and prescribing statins

- Recording blood pressure for patients older than 45

- Recording smoking status and ongoing management

- Recording body mass index (BMI) for patients with a BMI greater than 30 .

General practice profiles suggest that there is still variation between practices in the collection of this data - for example, smoking status recorded in the past 12 months ranges from $75.4 \%$ to $99.1 \% .^{15}$

Primary care teams are well placed to proactively deliver evidence based and cost-effective brief intervention advice to patients. The evidence for this is strongest for reducing smoking. ${ }^{16}$ In Liverpool, primary care was incentivised to deliver brief intervention advice in the context of a broader population-wide strategy, SmokeFree Liverpool (Box 2). Other examples of interventions include screening and brief interventions for alcohol, delivered through primary care and other partners and the National Health Check program, although the evidence supporting this program is hotly debated. ${ }^{17}$

Evidence shows that risk factors tend to cluster together and that a more nuanced, patient-centred approach that promotes self-care is required. ${ }^{18}$ Healthy Liverpool is supporting a city-wide program to increase levels of physical activity that has been strongly backed by local GPs.

Box 2. SmokeFree Liverpool and smoking cessation

SmokeFree Liverpool is a system-wide partnership established to tackle one of Liverpool's biggest killers: smoking. The strategy was to achieve local smokefree legislation while encouraging local workplaces to become voluntarily smoke-free, and establishing a comprehensive smoking cessation service. Primary care was incentivised to offer smoking cessation advice and referral to the specialist cessation service. Between 2005 and 2012 , smoking prevalence fell from $35 \%$ to $24.5 \%$. At its peak, $50 \%$ of referrals to the smoking cessation service came from primary care.

\section{Using primary care data}

General practice registration lists vary in size but average 7000 patients. In Liverpool, registered patients live in a relatively defined geographical catchment.

Practice lists are an asset for primary care and an opportunity for population health. Primary care and public health specialists can analyse the data to shape interventions and activities to promote health. This is an underused resource, with potential for risk stratification, monitoring, benchmarking, measuring inequalities, and identifying trends at practice, neighbourhood and locality levels. Applying segmentation principles to the practice lists can identify target groups for appropriate prevention interventions. There is also a need to collect data to more accurately answer key questions for population health.

In Liverpool, GP practices are organised into 18 neighbourhoods and three localities. Public health specialists have worked with primary care and used data from a range of sources to develop a health profile for each neighbourhood, which describes health needs and assets, and to identify priorities in each neighbourhood. The challenge for public health teams is to go further than describing the neighbourhoods: to work alongside primary care teams and the wider community to help with workforce planning and with developing and evaluating strategies and interventions to address needs. Again, this is not a new idea: an earlier example of this approach was developed, albeit with less sophisticated information systems, in the early 1990s as part of the Croxteth Health Action Plan. ${ }^{9}$

\section{Understanding and responding to patient and community needs and assets}

GPs are in a strong position to lead primary care teams to act on the health needs and assets of their communities. In Liverpool, innovative GPs have worked with local communities to identify and address the causes of ill health. For example, one practice proactively identified low levels of vitamin D in its Somali population and, in collaboration with local Somali groups, devised health promotion activities and a screen-and-treat program at the practice level. This paved the way for universal vitamin D supplementation in Liverpool.

GPs are often the first port of call for people struggling to cope with life. Marmot has argued that GPs should take a social history along with a medical history, leading to different conversations and solutions. ${ }^{19}$ The relationship between debt, poverty and poor mental health is well recognised. More than 20 years ago, a south Liverpool neighbourhood piloted the use of welfare advice within GP practices. In 2012, a local GP reported an increase in the number of people presenting with problems borne out of financial hardship. In response, the city's Advice on Prescription project was developed, and all GPs can now refer patients to the Citizens Advice Bureau for welfare, benefits, debt and housing advice. The impact of this in 
Liverpool is yet to be evaluated, but studies suggest that this approach is effective in reducing demand on the NHS and improving health outcomes. ${ }^{20}$

Being connected to social networks and 'place' is increasingly recognised as an influence on people's health. ${ }^{21}$ GPs can now access details of services in the community through a web application, and this has led to an increase in what is loosely termed 'social prescribing'. The key here is that patients' care plans link explicitly to informal support available in the local area.

Primary care is itself a community asset that can be capitalised on through integration with other community partners to become a neighbourhood wellbeing hub, offering a range of services. Children's centres have demonstrated how this can work for children and families. The Bromley by Bow Centre in East London is often cited as a good example of a community health and wellbeing hub. ${ }^{22}$

\section{Addressing the wider determinants of health through advocacy and strong partnerships}

Addressing the wider determinants of health is often not under the direct control of primary care. However, primary care, in partnership with local providers, can improve health and reduce health service use. An example is the Healthy Homes Initiative, a partnership between GPs, environmental health and housing. It has been shown to keep people warm, safe, free from cold and damp, and is an efficient use of resources. ${ }^{23}$

Interventions such as these enable collection of data about the wider determinants of health. Frontline clinicians can be powerful advocates for communities when equipped with appropriate evidence from public health specialists who have the skills to identify measures that can be used to improve population health.

\section{Striking a balance between strategy and delivery}

The health system infrastructure contains a number of challenges. Public health departments are based in local authorities and arguably have less influence over primary care. A balance needs to be found between public health's strategic role in local government and its healthcare delivery on the frontline. Having public health specialists working alongside primary care teams at a local level helps primary care to take a greater lead in population health. However, it is essential that the success, or otherwise, of population health interventions is measured, as the need to demonstrate impact remains.

\section{Liverpool: a city that can deliver on population health?}

The Healthy Liverpool program clearly sets out a vision for developing a population health approach. Delivery of the program will be overseen by the Liverpool Health and
Wellbeing Board. The Liverpool Clinical Commissioning Group, led by GPs, is now responsible for commissioning primary care, community services and secondary care, and is better positioned than ever to align its resources to improve population health.

The examples cited in this article show that there is a rich history to build on, but delivery needs to be sustainable and at scale. Local public health budgets are being significantly reduced. It is therefore imperative that the system works as a whole to achieve the aim of improved population health.

Much of the focus in the past year has been on integrating primary, community and social services to deliver person-centred care. The emphasis has remained on the urgent need to prevent unnecessary hospital admissions, which will do little to improve population health. However, the focus on integrating care does present the opportunity for services to interact differently with communities. We now need to increase the momentum to drive a shift in culture from a reactive system to one that is proactive and preventive. This will require a strong vision and visible GP leadership for population health. System enablers include:

- Shared information technology systems

- Workforce planning and development to enable primary care teams to develop innovative ways to deliver population health

- Commissioning for population health outcomes

- Performance management that values organisational collaboration

- Consideration of incentives for specific targeted work.

\section{Conclusion}

Integrating primary care and public health has been on the agenda for the past 30 years. Outcomes have varied for a number of reasons, not least because of the availability of resources. Clinical commissioning groups are now clinically led and clinically accountable for commissioning most health services for their populations and have a vested interest in improving population health outcomes. The opportunity exists now to align resources to prioritise prevention, work alongside communities and empower people to take more control over their health.

\section{Competing interests}

None declared

\section{Author contributions}

RG designed, drafted and edited the manuscript; $\mathrm{SD}$ reviewed the manuscript and $\mathrm{JH}$ designed, reviewed and edited the manuscript. 


\section{References}

1. Dahlgren $\mathrm{G}$, Whitehead M. European strategies for tackling inequalities in health. Levelling up part 2; p80. Copenhagen: World Health Organization Regional Office for Europe; 2007 [cited 2015 Dec 9 ]. Available from: www.euro.who.int/_data/assets/pdf_file/0018/103824/ E89384.pdf

2. The King's Fund. Making the case for public health interventions. 2014 [cited 2015 Dec 9] [about 5 screens]. Available from: www.kingsfund.org.uk/audio-video/publichealth-spending-roi

3. Frazer WM, Ashton J (Ed). Duncan of Liverpool: an account of the work of Dr W M Duncan, medical officer of health of Liverpool, 1847-1863 [facsimile]. London: Carnegie Publishing; 1997.

4. The World Health Organization. Ottawa charter for health promotion. Geneva: WHO; 1986 [cited 2015 Dec 9]. Available from: www.who.int/healthpromotion/ conferences/previous/ottawa/en/

5. NHS England. Five year forward view. NHS England; 2014 [cited 2015 Dec 9]. Available from: www.england. nhs.uk/wp-content/uploads/2014/10/5yfv-web.pdf

6. Director of Public Health for Liverpool. Annual Report of the Director of Public Health 2014. Liverpool: Liverpool City Council; 2014 [cited 2015 Dec 9]. Available from: www.champspublichealth.com/sites/default/files/media_ library/75205_LCC\%2052pp\%20Text.pdf

7. World Health Organization. Declaration of Alma-Ata: international conference on primary health care, AlmaAta, USSR, 6-12 September 1978 (Part I). Alma-Ata: WHO; 1978 [cited 2015 Jul 15]. Available from: www.who. int/publications/almaata_declaration_en.pdf

8. Peckham S, Hann A, Boyce T. Health promotion and ill health prevention: the role of general practice. Qual Prim Care. 2011;19(5):317-23.

9. Hussey R. Croxteth health action area health information: Liverpool Healthy Cities Research Consortium. Liverpool: University of Liverpool; 1990.

10. Liverpool Clinical Commissioning Group. Healthy Liverpool prospectus for change. Liverpool: NHS; 2014 [cited 2015 Dec 9]. Available from: www.liverpoolccg. nhs.uk/Library/Get_involved/Healthy\%20Liverpool\%20 Prospectus\%20for\%20Change_Final.pdf

11. National Institute for Health and Care Excellence. Guidance list. c2015 [cited 2015 Dec 9] [about 1 screen]. Available from: www.nice.org.uk/guidance/ published?type $=$ ph
12. Gottlieb K. The Nuka system of care: improving health through ownership and relationships. Int J Circumpolar Health. 2013;72:21118.

13. Keck CW, Reed GA. The curious case of Cuba. Am J Public Health. 2012;102(8):e13-e22.

14. Alderwick H, Ham C, Buck D. Population health systems: going beyond integrated care. London: The Kings Fund; 2015 [cited 2015 Dec 9]. Available from: www.kingsfund. org.uk/sites/files/kf/field/field_publication_file/populationhealth-systems-kingsfund-feb15.pdf

15. Public Health England. National general practice profiles. 2015 [cited 2015 Dec 9] [online database]. Available from: fingertips.phe.org.uk/profile/general-practice/data

16. National Institute for Health and Care Excellence. Smoking: brief interventions and referrals. London: NICE; 2006 [cited 2015 Dec 9]. Available from: www.nice.org. uk/guidance/ph1

17. Capewell S, McCartney M, Holland W. NHS Health Checks - a naked emperor? J Public Health (Oxf). 2015;37(2):187-92.

18. Buck D, Frosini F. Clustering of unhealthy behaviours over time: implications for policy and practice. London: The Kings Fund; 2012 [cited 2015 Dec 9]. Available from: www.kingsfund.org.uk/sites/files/kf/field/field_publication_ file/clustering-of-unhealthy-behaviours-over-timeaug-2012.pdf

19. Atkinson S, Cottam B. How doctors can close the gap: tackling the social determinants of health. Clin Med. 11(1):57-60.

20. Consilium Research Consultancy. The role of advice services in health outcomes: evidence review and mapping study. London: Advice Services Alliance; 2015 [cited 2015 Dec 9]. Available from: www. thelegaleducationfoundation.org/wp-content/ uploads/2015/06/Role-of-Advice-Services-in-HealthOutcomes.pdf

21. Buck D, Maguire D. Inequalities in life expectancy: changes over time and implications for policy. London: The Kings Fund; 2015 [cited 2015 Dec 9]. Available from: www.kingsfund.org.uk/sites/files/kf/field/field_publication_ file/inequalities-in-life-expectancy-kings-fund-aug15.pdf

22. The Kings Fund. The future is now: the innovations of today that point to better health care tomorrow. London: The Kings Fund; 2015 [cited 2015 Dec 9]. Available from: www.kingsfund.org.uk/reports/thefutureisnow/

23. Buck D, Gregory S. Improving the public's health: a resource for local authorities. London: The Kings Fund; 2013 [cited 2015 Dec 15]. Available from: www.kingsfund.org.uk/sites/files/kf/field/field_publication_ file/improving-the-publics-health-kingsfund-dec13.pdf

\section{Copyright: (cc)}

(c) 2016 Gosling et al. This article is licensed under the Creative Commons Attribution-NonCommercial-ShareAlike 4.0 International Licence, which allows others to redistribute, adapt and share this work non-commercially provided they attribute the work and any adapted version of it is distributed under the same Creative Commons licence terms. See: www.creativecommons.org/licenses/by-nc-sa/4.0/ 